\title{
ORIGINAL
}

\section{INGESTA DE ALIMENTOS, ENERGÍA Y NUTRIENTES EN LA POBLACIÓN DE 5 A 12 AÑOS DE LA COMUNIDAD DE MADRID: RESULTADOS DE LA ENCUESTA DE NUTRICIÓN INFANTIL 2001-2002}

\author{
Lucía Díez-Gañán (1), Iñaki Galán Labaca (1), Carmen María León Domínguez (2), Ana Gandarillas \\ Grande (1), Belén Zorrilla Torras (1) y Francisca Alcaraz Cebrián (3).
}

(1) Servicio de Epidemiología. Instituto de Salud Pública. Dirección General de Salud Pública y Alimentación. Consejería de Sanidad. Comunidad de Madrid.

(2) Servicio de Alertas en Salud Pública. Dirección General de Salud Pública y Alimentación. Consejería de Sanidad y Consumo. Comunidad de Madrid.

(3) Servicio de Nutrición. Hospital Ramón y Cajal. Comunidad de Madrid.

\section{RESUMEN}

Fundamento: Para conocer la situación alimentaria y nutricional en la población infantil, sobre la que no existía información actualizada, el Instituto de Salud Pública desarrolló la Encuesta de Nutrición Infantil de la Comunidad de Madrid 2001/2002 (ENICM). En este trabajo se analiza la ENICM para describir y evaluar la ingesta de alimentos, energía y nutrientes en esta población.

Métodos: Estudio transversal sobre una muestra representativa de la población de 5-12 años de la Comunidad de Madrid. La información alimentaria se recogió en 2001 y 2002 mediante dos recuerdos de 24 horas. Se ha estudiado la ingesta total diaria de alimentos, energía y nutrientes. Los análisis incluyen los 1.852 niños con información completa en los dos recuerdos (90,8\% de las entrevistas realizadas).

Resultados: La ingesta media total diaria de alimentos es $1.460,7$ gramos/persona/día. Salvo para los lácteos, huevos y aceites, la ingesta en los grupos alimentarios básicos es inadecuada, particularmente baja en las frutas frescas, verduras y hortalizas. La ingesta media energética y nutricional resultante es $1.905,9 \mathrm{kcal} /$ persona/día; 43,6\% hidratos de carbono; 17,4\% proteínas, 39,0\% lípidos (13,3\% grasas saturadas, $16,8 \%$ monoinsaturadas, $5,0 \%$ poliinsaturadas); $363,8 \mathrm{mg}$ de colesterol; 13,6 $\mathrm{g}$ de fibra e ingestas por debajo de las recomendadas de zinc, ácido fólico, vitaminas D y E (ambos sexos) y hierro y vitamina B6 (niñas)

Conclusiones: La dieta de la población infantil de la Comunidad de Madrid presenta desequilibrios que es necesario mejorar: ingesta inadecuada de alimentos básicos, exceso de proteínas, grasas saturadas y colesterol y déficit de hidratos de carbono, fibra y algunos micronutrientes.

Palabras clave: Ingesta de energía. Ingesta de alimentos. Infancia. Estudio transversal. Encuesta alimentaria. España.

Correspondencia:

Lucía Díez-Gañán

Servicio de Epidemiología

Instituto de Salud Pública

Consejería de Sanidad

C/ Julián Camarillo $\mathrm{N}^{\circ} 4 \mathrm{~B}$

28037 Madrid

Correo electrónico: lucia.diez@salud.madrid.org

\section{ABSTRACT}

\section{Food, Energy and Nutrient Intake in Children Aged 5-12 in the Autonomous} Community of Madrid, Spain: Results of the 2001/2002 Children's Nutrition Survey

Backgound: In order to ascertain the food intake and nutritional situation of the children of the Community of Madrid, on which no updated information was available, the Institute of Public Health conducted the 2001/2001 Children's Nutrition Survey of the Community of Madrid (CNSCM). This study offers an analysis of the CNSCM that describes and evaluates the food, energy and nutrient intake of this segment of the population.

Methods: Cross-sectional survey on a representative sample of children aged 5-12 years from the Community of Madrid. Dietrelated information was collected in 2001 and 2002 by means of two 24-hour recalls. Total daily food, energy and nutrient intake were studied. The analysis included only the 1852 children who had completed both 24 -h recalls ( $90.8 \%$ of all interviews).

Results: The average daily food intake is 1460.7 grams/person/day. Except for dairy products, eggs and oils, intake from the basic food groups is inadequate, and is particularly low for fresh fruits, green leafy vegetables and garden vegetables in general. The resulting average energy and nutrition intake is 1905.9 $\mathrm{kcal} /$ person/day; $43.6 \%$ carbohydrates, $17.4 \%$ proteins, $39.0 \%$ fats $(13.3 \%$ saturated fats, $16.8 \%$ monosaturated fats, $5.0 \%$ polyunsaturated fats); $363.8 \mathrm{mg}$ cholesterol, $13.6 \mathrm{~g}$ of fiber and lower than recommended intakes of zinc, folic acid, vitamins D and E (both sexes) and iron and vitamin B6 (girls).

Conclusions: The diet of the children of the Community of Madrid shows a number of imbalances that should be improved: inadequate intake from basic food groups; excess of proteins, saturated fats and cholesterol; and a deficit of carbohydrates, fiber and certain micronutrients.

Key words: Energy intake. Food intake. Children. Crosssectional studies. Nutrition surveys. Diet surveys. Spain. 


\section{INTRODUCCIÓN}

La alimentación es uno de los principales determinantes del estado de salud del ser humano y el factor extrínseco más importante para su desarrollo ${ }^{1,2}$. Una alimentación adecuada es fundamental a lo largo de toda la vida, pero durante la infancia es particularmente crucial pues las carencias y desequilibrios nutricionales en esta etapa tienen consecuencias negativas no sólo en la salud del propio niño (retraso del crecimiento, retraso en el desarrollo psicomotor, disminución de la capacidad de aprendizaje, desarrollo de obesidad, incremento del riesgo de infecciones y otras enfermedades, incremento del riesgo de mortalidad general $)^{1,2}$, sino que pueden condicionar su salud durante la vida adulta, aumentando el riesgo de desarrollar trastornos crónicos (cáncer, hipertensión arterial, cardiopatía isquémica y otras enfermedades cardiovasculares, enfermedades cerebrovasculares, diabetes mellitus tipo 2, obesidad, osteoporosis $)^{1-3}$, las cuales constituyen las principales causas de mortalidad y/o morbilidad y discapacidad en España ${ }^{4}$. En concreto en la Comunidad de Madrid las enfermedades del sistema circulatorio y el cáncer ocasionan desde hace años más de dos tercios de las muertes anuales ${ }^{5-8}$.

En la actualidad sabemos que estas enfermedades están relacionadas con la dieta desequilibrada, la falta de actividad física o sedentarismo, el consumo de alcohol y el consumo de tabaco ${ }^{9-13}$ y que estos riesgos, que se acumulan desde las etapas más tempranas de la vida, se pueden disminuir e incluso eliminar una vez presentes y, aún más importante si cabe, prevenir su aparición actuando desde la infancia, que es cuando se produce el aprendizaje y adquisición de los hábitos alimentarios y otros estilos de vida ${ }^{14-19}$. La influencia de diversos factores (económicos, políticos, socioculturales, educativos, individuales) induce cambios en los patrones alimentarios, cambios no siempre conformes con las recomenda- ciones para una correcta nutrición, lo que requiere un seguimiento de la dieta para adaptar o reforzar oportunamente las estrategias de intervención ${ }^{20-23}$.

El Instituto de Salud Pública, dentro de sus competencias de vigilancia de los factores relacionados con la salud de la población para orientar las intervenciones en salud pública, desarrolló la Encuesta de Nutrición Infantil de la Comunidad de Madrid 2001/2002 para conocer y evaluar la situación alimentaria y nutricional actual de la población infantil de la Comunidad de Madrid (sobre la que no existía información), identificar posibles riesgos nutricionales y examinar la relación de la alimentación y nutrición con otras características y hábitos de vida relacionados con la salud.

El objetivo del presente trabajo es describir la ingesta de alimentos, energía y nutrientes en la población infantil de 5 a 12 años de la Comunidad de Madrid.

\section{SUJETOS Y MÉTODOS}

\section{Tipo de estudio y población estudiada}

La Encuesta de Nutrición Infantil de la Comunidad de Madrid 2001/2002 (ENICM) es un estudio transversal poblacional sobre los sujetos de 5 a 12 años de edad de esta región. En 2001 se obtuvo una muestra de 2.039 niños, 1.060 varones $(52,0 \%)$ y 979 niñas $(48,0 \%)$, representativa de esta población, seleccionada mediante un muestreo estratificado por edad, sexo y área sanitaria, a partir de la tarjeta sanitaria que, comparada con el censo de 2001, se estima que tiene una cobertura del $91,1 \%$ en la Comunidad de Madrid.

\section{Información recogida}

Entrevistadores formados específicamente para el estudio recogieron la infor- 
mación de la ENICM durante los años 2001 y 2002 mediante entrevista telefónica con el sistema Computer Assisted Telephone Interview $(\mathrm{CATI})^{24}$. La entrevista fue respondida por el representante legal del niño (madre, padre u otro tutor legal). En primer lugar, se solicitó la participación en el estudio del miembro de la familia encargado de la alimentación del niño. Cuando no fue posible entrevistar a esta persona se realizó la entrevista a alguno de los otros miembros del hogar encargado del cuidado del niño. Mediante un cuestionario estructurado se recogió información sociodemográfica del niño y su entorno familiar, información alimentaria y otras características y hábitos de vida del niño relacionados con la salud (peso, talla, actividad física, actividad en tiempo de ocio y otras variables). Con anterioridad a la recogida en 2001 y 2002 de la información de los 2.039 sujetos incluidos en la ENICM se realizó en 2001 un estudio piloto con 120 niños/as para comprobar el funcionamiento del cuestionario y el proceso de entrevista y corregir posibles problemas. La herramienta empleada para recoger la información alimentaria fue el recuerdo de 24 horas, que se eligió y diseñó de acuerdo con los objetivos del estudio ${ }^{25-27}$. De cada niño/a se obtuvieron dos recuerdos de 24 horas completos en estaciones diferentes del año y asegurando la proporcionalidad de días laborables y festivos, con el fin de evitar estimaciones sesgadas por la variabilidad estacional o diaria ${ }^{28-30}$. En cada recuerdo se registró la ingesta de alimentos del día anterior a la entrevista [alimento, cantidad ingerida en medidas caseras, marca (si procedía, como en los alimentos procesados de elaboración industrial), hora y lugar de la ingesta] separadamente para cada una de las ocasiones o momentos del día en los que puede ingerirse algún alimento, seis en total: desayuno, media mañana, comida, merienda, cena y entre horas. La suma de la ingesta de todos los momentos del día es la ingesta total que el sujeto había realizado durante el día. Las cantidades de alimentos y bebidas ingeridas se determina- ron con el apoyo de un diccionario de alimentos y cantidades estándar, elaborado bajo la dirección de una dietista, contemplando todas las medidas caseras a las que podían referirse las personas entrevistadas. Pesando cada medida casera se determinó su cantidad neta en gramos crudos (sólidos) o centímetros cúbicos (líquidos). A continuación, mediante las tablas de composición de alimentos de Moreiras y colaboradores $^{31}$, se realizó la conversión de los alimentos ingeridos a energía y nutrientes.

\section{Análisis}

Se realizó un análisis descriptivo de la ingesta de alimentos, energía y nutrientes. Se calculó el porcentaje de niños que comen alguna cantidad de los distintos alimentos. Se estudió la distribución en la población de la ingesta media total diaria de alimentos, energía, hidratos de carbono, proteínas, lípidos totales, ácidos grasos saturados, monoinsaturados y poliinsaturados, colesterol, fibra, minerales y vitaminas, calculando para cada uno de ellos la media, desviación estándar (DE) y los percentiles 25, 50 y 75 (P25, P50 y P75). Se calculó la equivalencia en raciones de las cantidades netas ingeridas de los grupos alimentarios básicos (cereales y tubérculos; leche y derivados lácteos; verduras y hortalizas; frutas frescas; carnes, pescados, huevos y legumbres; grasas y aceites $)^{27}$ empleando la tabla de "Pesos de raciones por grupos y medidas caseras" de la Sociedad Española de Nutrición Comunitaria (SENC) $)^{32}$. Se examinó la contribución porcentual de los macronutrientes a la ingesta diaria de energía (perfil calórico) y se estimó la razón media de ácidos grasos no saturados/ácidos grasos saturados ingeridos. Para la energía, proteínas y micronutrientes se calcularon también las ingestas medias como porcentaje de las ingestas recomendadas (IR) para la población española por el Departamento de Nutrición de la Universidad Complutense de Madrid ${ }^{33}$. Esto permitió detectar riesgos de ingestas nutricionales 
inadecuadas (deficientes o excesivas: ingesta media $<100 \%$ ó $>100 \%$, respectivamente, de la IR) ${ }^{34 ; 35}$, lo cual es a su vez un indicador del riesgo nutricional que puede existir en la población ${ }^{34 ; 35}$. Las ingestas recomendadas representan las cantidades que se estima necesario ingerir para satisfacer los requerimientos o necesidades de nutrientes en al menos el 97-98\% de la población y de energía en al menos el 50\% $25-27 ; 33$, y se establecen teniendo en cuenta las necesidades nutricionales estimadas en la población según el sexo, edad y situación vital (infancia, adolescencia, edad adulta, vejez, embarazo, lactancia) y asumiendo una actividad física moderada ${ }^{33}$. Por último, se examinó la situación de la población respecto a los objetivos nutricionales recomendados por la $\mathrm{SENC}^{36}$, y la ingesta de frutas frescas, verduras y hortalizas en comparación también con la recomendación de la Organización Mundial de la Salud (OMS) ${ }^{37}$.

En los análisis se incluyeron sólo los niños con información alimentaria completa en los dos recuerdos de 24 horas, ya que la ingesta alimentaria y nutricional de cada individuo es el promedio resultante de sus dos recuerdos, lo cual aumenta la precisión y validez de las estimaciones como indicadores de la dieta actual y de la dieta habitual $^{25-30}$. Los resultados se presentan para toda la población y por sexo. Los análisis se realizaron con el paquete estadístico SAS $@$, versión $8.2^{38}$.

\section{RESULTADOS}

La tasa de respuesta, medida como el número de entrevistas realizadas completas (aquéllas que presentan información alimentaria completa en los dos recuerdos) dividido entre el número total de entrevistas realizadas (completas más incompletas) más las no realizadas (lo que incluye las negativas y los no contactos -ilocalizables o teléfono erróneo) fue del $67,2 \%$. La tasa de cooperación, expresada como el cociente de las entrevistas rea- lizadas completas entre todas las realizadas más las negativas, fue del $85,5 \%$. En total, se recogió información válida y completa en los 2 recuerdos de 24 horas de 1.852 niños/as de 5 a 12 años, 958 varones $(51,7 \%)$ y 894 niñas $(48,3 \%)$, lo que representa el $90,8 \%$ de las entrevistas realizadas. La media de edad de la población estudiada fue de 8,8 años (DE: 2,0 años). La persona encargada habitualmente de planificar el menú del niño fue en el $85,2 \%$ de los casos la madre y en el $1,6 \%$ el padre, mientras un $6,9 \%$ refirió compartir la responsabilidad (madre y padre) y en un $6,3 \%$ de los casos se ocupaba otro familiar o cuidador del niño. Fue también la madre la que cocinaba habitualmente el menú del niño con mucha más frecuencia que el padre (76,8\% de los niños sólo madre; $9,1 \%$ responsabilidad compartida madre-padre; $2,0 \%$ sólo padre; $12,1 \%$ otra persona). En el 89,0\% de las ocasiones la entrevista fue respondida por la persona encargada habitualmente de la alimentación del niño.

\section{Ingesta de alimentos}

La tabla 1 recoge el porcentaje de sujetos que come alguna cantidad de los distintos alimentos y las cantidades ingeridas. La ingesta media total diaria de alimentos en la población de 5 a 12 años de la Comunidad de Madrid es de 1.460,7 gramos/persona/día (DE: 312,7 g/persona/día), de los que 959,1 g son alimentos sólidos o semisólidos y algo más de la tercera parte se realiza en forma de líquidos: leche y bebidas comerciales procesadas de elaboración industrial (501,6 cc/persona/día) (no incluye el agua de bebida).

Prácticamente todos los niños $(99,9 \%)$ comíann cereales a lo largo del día (ingesta media: 125,4 g/persona/día, unas 2,5 raciones/persona/día). Sobre todo pan, del que casi todos $(98,0 \%)$ comían alguna cantidad al día, y cuya ingesta media representaba unas 2 raciones/persona/día de cereales, seguido de arroz y pasta, cereales para el desayuno y otros cereales, que eran ingeridos por un 
Tabla 1

Ingesta de alimentos en la población de 5-12 años de la Comunidad de Madrid: población consumidora (\%)*, ingesta media y desviación estándar (DE), y percentiles 25,50 y 75 . Total y por sexo. ENICM 2001/2002

\begin{tabular}{|c|c|c|c|c|c|c|c|c|c|c|c|c|c|c|c|}
\hline \multirow{4}{*}{ Alimento $(\mathrm{g} ; \mathrm{cc})^{* *}$} & \multicolumn{5}{|c|}{ Total $(\mathrm{n}=1852)$} & \multicolumn{5}{|c|}{ Niños (n=958) } & \multicolumn{5}{|c|}{ Niñas $(\mathrm{n}=894)$} \\
\hline & \multirow{3}{*}{$\% *$} & \multicolumn{4}{|c|}{ Ingesta (persona/día) } & \multirow{3}{*}{$\% *$} & \multicolumn{4}{|c|}{ Ingesta (persona/día) } & \multirow{3}{*}{$\% *$} & \multicolumn{4}{|c|}{ Ingesta (persona/día) } \\
\hline & & \multirow{2}{*}{ Media (DE) } & \multicolumn{3}{|c|}{ Percentil } & & \multirow{2}{*}{ Media (DE) } & \multicolumn{3}{|c|}{ Percentil } & & \multirow{2}{*}{ Media (DE) } & \multicolumn{3}{|c|}{ Percentil } \\
\hline & & & 25 & 50 & 75 & & & 25 & 50 & 75 & & & 25 & 50 & 75 \\
\hline Cereales y derivados & 99,9 & $125,4 \quad(54,5)$ & 86,0 & 118,5 & 156,5 & 99,9 & $133,6 \quad(57,7)$ & 91,0 & 126,5 & 166,0 & 99,9 & $116,5 \quad(49,4)$ & 80,5 & 111,5 & 145,5 \\
\hline Arroz y pasta & 79,9 & $26,6 \quad(22,8)$ & 7,5 & 22,5 & 40,0 & 81,0 & $28,0 \quad(23,5)$ & 9,0 & 26,5 & 42,5 & 78,7 & $25,1 \quad(21,9)$ & 7,5 & 22,5 & 37,5 \\
\hline Pan & 98,0 & $84,0 \quad(48,5)$ & 50,0 & 76,0 & 110,0 & 97,9 & $90,9 \quad(52,4)$ & 55,0 & 85,0 & 118,0 & 98,1 & $76,6 \quad(42,8)$ & 47,5 & 70,5 & 100,0 \\
\hline Cereales para el desayuno & 45,2 & $8,8 \quad(13,4)$ & 0,0 & 0,0 & 15,0 & 44,1 & $9,1 \quad(14,3)$ & 0,0 & 0,0 & 15,0 & 46,4 & $8,5 \quad(12,4)$ & 0,0 & 0,0 & 15,0 \\
\hline Otros cereales & 58,8 & $5,9 \quad(9,6)$ & 0,0 & 2,5 & 7,5 & 59,5 & $5,6 \quad(8,0)$ & 0,0 & 3,0 & 7,5 & 58,1 & $6,2 \quad(11,1)$ & 0,0 & 2,5 & 7,5 \\
\hline Leche y derivados lácteos & 99,8 & $508,2(181,1)$ & 387,5 & 493,8 & 612,5 & 99,7 & $521,2(189,0)$ & 395,0 & 503,0 & 644,0 & 100,0 & $494,3(171,2)$ & 380,0 & 484,5 & 590,0 \\
\hline Leche & 97,7 & $369,7 \quad(170,3)$ & 250,0 & 350,0 & 475,0 & 97,2 & $377,7(180,2)$ & 250,0 & 362,5 & 486,5 & 98,3 & $361,2(158,7)$ & 250,0 & 350,0 & 450,0 \\
\hline Quesos & 55,9 & $10,4 \quad(15,3)$ & 0,0 & 3,8 & 16,0 & 54,3 & $10,0 \quad(15,3)$ & 0,0 & 2,5 & 15,0 & 57,7 & $10,9 \quad(15,3)$ & 0,0 & 5,0 & 16,0 \\
\hline Yogures & 70,1 & $80,5 \quad(76,2)$ & 0,0 & 62,5 & 125,0 & 72,3 & $83,6 \quad(77,3)$ & 0,0 & 62,5 & 125,0 & 67,8 & $77,1 \quad(74,9)$ & 0,0 & 62,5 & 125,0 \\
\hline Otros derivados y postres lácteos & 55,5 & $47,6 \quad(62,7)$ & 0,0 & 27,5 & 67,5 & 55,4 & $49,9 \quad(65,8)$ & 0,0 & 27,5 & 72,5 & 55,5 & $45,2 \quad(59,1)$ & 0,0 & 27,5 & 67,5 \\
\hline Verduras y hortalizas & 92,5 & $88,9 \quad(75,4)$ & 29,3 & 72,0 & 127,5 & 92,7 & $87,3 \quad(74,8)$ & 29,5 & 67,8 & 126,0 & 92,3 & $90,6 \quad(76,0)$ & 29,0 & 76,0 & 128,0 \\
\hline Tubérculos & 83,9 & $73,3 \quad(61,5)$ & 18,5 & 67,5 & 110,0 & 85,8 & $77,5 \quad(63,8)$ & 25,5 & 67,5 & 116,5 & 81,9 & $68,8 \quad(58,6)$ & 17,0 & 67,0 & 102,0 \\
\hline Frutas frescas & 93,1 & $193,1 \quad(133,3)$ & 88,3 & 172,5 & 268,5 & 92,1 & $187,6(136,3)$ & 84,0 & 166,0 & 258,0 & 94,3 & $199,0(129,8)$ & 100,0 & 181,8 & 280,5 \\
\hline Frutas frescas oleaginosas & 10,6 & $2,2 \quad(7,9)$ & 0,0 & 0,0 & 0,0 & 9,3 & $1,9 \quad(7,5)$ & 0,0 & 0,0 & 0,0 & 12,0 & $2,4 \quad(8,4)$ & 0,0 & 0,0 & 0,0 \\
\hline Frutas desecadas & 0,6 & $0,1 \quad(1,2)$ & 0,0 & 0,0 & 0,0 & 0,9 & $0,1 \quad(1,3)$ & 0,0 & 0,0 & 0,0 & 0,3 & $0,1 \quad(1,1)$ & 0,0 & 0,0 & 0,0 \\
\hline Conservas de frutas & 20,2 & $4,3 \quad(14,4)$ & 0,0 & 0,0 & 0,0 & 19,4 & $4,7 \quad(16,0)$ & 0,0 & 0,0 & 0,0 & 21,1 & $3,8 \quad(12,5)$ & 0,0 & 0,0 & 0,0 \\
\hline Frutos secos & 8,3 & $0,9 \quad(4,9)$ & 0,0 & 0,0 & 0,0 & 7,4 & $0,9 \quad(4,9)$ & 0,0 & 0,0 & 0,0 & 9,2 & $1,0 \quad(4,8)$ & 0,0 & 0,0 & 0,0 \\
\hline Legumbres & 40,5 & $11,2 \quad(16,0)$ & 0,0 & 0,0 & 25,0 & 40,9 & $11,5 \quad(16,2)$ & 0,0 & 0,0 & 25,0 & 40,0 & $11,0 \quad(15,7)$ & 0,0 & 0,0 & 25,0 \\
\hline Huevos & 78,8 & $24,4 \quad(23,9)$ & 4,0 & 22,0 & 36,5 & 79,5 & $26,1 \quad(24,7)$ & 5,0 & 26,5 & 38,5 & 78,0 & $22,7 \quad(22,8)$ & 2,5 & 18,0 & 35,5 \\
\hline Carnes & 96,0 & $104,9 \quad(61,8)$ & 60,5 & 100,0 & 144,0 & 96,8 & $108,2 \quad(62,6)$ & 65,0 & 102,8 & 147,0 & 95,2 & $101,4 \quad(60,9)$ & 57,5 & 99,0 & 140,0 \\
\hline Embutidos & 87,0 & $35,4 \quad(30,0)$ & 12,5 & 30,0 & 50,3 & 89,2 & $36,7 \quad(30,0)$ & 15,0 & 30,3 & 52,5 & 84,7 & $34,0 \quad(30,0)$ & 11,5 & 29,3 & 49,0 \\
\hline Pescados & 50,3 & $35,5 \quad(45,6)$ & 0,0 & 3,3 & 60,8 & 51,5 & $37,3 \quad(46,4)$ & 0,0 & 14,0 & 62,5 & 49,1 & $33,6 \quad(44,6)$ & 0,0 & 0,0 & 56,5 \\
\hline Moluscos y crustáceos & 21,1 & $5,5 \quad(14,7)$ & 0,0 & 0,0 & 0,0 & 19,9 & $5,5 \quad(16,0)$ & 0,0 & 0,0 & 0,0 & 22,4 & $5,4 \quad(13,1)$ & 0,0 & 0,0 & 0,0 \\
\hline $\begin{array}{l}\text { Conservas de pescados, moluscos } \\
\text { y crustáceos }\end{array}$ & 18,5 & $2,9 \quad(8,2)$ & 0,0 & 0,0 & 0,0 & 17,6 & $2,9 \quad(8,3)$ & 0,0 & 0,0 & 0,0 & 19,4 & $3,0 \quad(8,0)$ & 0,0 & 0,0 & 0,0 \\
\hline Aceites y grasas añadidas & 100,0 & $27,5 \quad(8,8)$ & 22,5 & 25,5 & 30,0 & 100,0 & $27,9 \quad(9,1)$ & 22,5 & 26,5 & 30,0 & 100,0 & $27,1 \quad(8,4)$ & 22,5 & 25,0 & 30,0 \\
\hline Aceites & 100,0 & $23,3 \quad(4,9)$ & 20,0 & 25,0 & 27,5 & 100,0 & $23,5 \quad(4,8)$ & 20,0 & 25,0 & 27,5 & 100,0 & $23,1 \quad(5,0)$ & 20,0 & 23,0 & 27,5 \\
\hline Mantequilla & 15,6 & $1,5 \quad(4,6)$ & 0,0 & 0,0 & 0,0 & 15,8 & $1,5 \quad(4,8)$ & 0,0 & 0,0 & 0,0 & 15,3 & $1,4 \quad(4,3)$ & 0,0 & 0,0 & 0,0 \\
\hline Margarina & 28,5 & $2,6 \quad(5,9)$ & 0,0 & 0,0 & 2,0 & 28,7 & $2,8 \quad(6,3)$ & 0,0 & 0,0 & 2,0 & 28,3 & $2,5 \quad(5,5)$ & 0,0 & 0,0 & 2,0 \\
\hline Otras grasas & 1,4 & $0,0 \quad(0,2)$ & 0,0 & 0,0 & 0,0 & 1,4 & $0,0 \quad(0,2)$ & 0,0 & 0,0 & 0,0 & 12,6 & $0,0 \quad(0,3)$ & 0,0 & 0,0 & 0,0 \\
\hline Repostería & 81,0 & $39,5 \quad(36,5)$ & 12,0 & 30,8 & 59,0 & 79,2 & $42,5 \quad(40,3)$ & 12,0 & 34,0 & 64,0 & 82,9 & $36,3 \quad(31,6)$ & 12,0 & 30,0 & 53,0 \\
\hline Azúcares y derivados & 92,4 & $16,5 \quad(14,0)$ & 7,0 & 13,0 & 22,5 & 91,4 & $16,9 \quad(14,9)$ & 7,0 & 13,0 & 23,0 & 93,4 & $16,1 \quad(13,0)$ & 7,5 & 12,8 & 22,0 \\
\hline $\begin{array}{l}\text { Aperitivos y chucherías saladas, } \\
\text { alimentos precocinados y salsas }\end{array}$ & 71,5 & $29,0 \quad(38,2)$ & 0,0 & 16,0 & 41,3 & 71,5 & $30,3 \quad(39,0)$ & 0,0 & 19,3 & 44,0 & 71,6 & $27,6 \quad(37,3)$ & 0,0 & 15,0 & 40,0 \\
\hline Aperitivos y chucherías saladas & 28,3 & $4,9 \quad(10,7)$ & 0,0 & 0,0 & 5,0 & 27,7 & $5,1 \quad(10,6)$ & 0,0 & 0,0 & 5,0 & 29,0 & $4,7 \quad(10,7)$ & 0,0 & 0,0 & 5,0 \\
\hline Alimentos precocinados & 20,7 & $12,9 \quad(32,0)$ & 0,0 & 0,0 & 0,0 & 19,9 & $12,8 \quad(32,6)$ & 0,0 & 0,0 & 0,0 & 21,5 & $12,9 \quad(31,3)$ & 0,0 & 0,0 & 0,0 \\
\hline Salsas & 52,5 & $11,2 \quad(16,9)$ & 0,0 & 2,5 & 20,0 & 55,6 & $12,3 \quad(17,8)$ & 0,0 & 3,0 & 20,0 & 49,2 & $10,0 \quad(15,7)$ & 0,0 & 0,0 & 20,0 \\
\hline $\begin{array}{l}\text { Bebidas comerciales procesadas de } \\
\text { elaboración industrial }\end{array}$ & 64,2 & $131,9(145,2)$ & 0,0 & 100,0 & 200,0 & 63,8 & $139,4(155,1)$ & 0,0 & 100,0 & 200,0 & 64,7 & $123,9(133,3)$ & 0,0 & 100,0 & 200,0 \\
\hline Zumos no naturales procesados & 44,8 & $76,2(108,8)$ & 0,0 & 0,0 & 100,0 & 43,0 & $75,9(112,5)$ & 0,0 & 0,0 & 100,0 & 46,6 & $76,6(104,9)$ & 0,0 & 0,0 & 100,0 \\
\hline Refrescos & 35,7 & $55,7 \quad(98,3)$ & 0,0 & 0,0 & 100,0 & 37,3 & $63,5(109,9)$ & 0,0 & 0,0 & 100,0 & 34,0 & $47,4 \quad(83,5)$ & 0,0 & 0,0 & 100,0 \\
\hline TOTAL líquidosì & 99,5 & $501,6(211,8)$ & 350,0 & 493,8 & 625,0 & 99,5 & $517,1 \quad(224,7)$ & 351,0 & 500,0 & 650,0 & 99,4 & $485,1 \quad(195,8)$ & 350,0 & 475,0 & 600,0 \\
\hline TOTAL alimentos sólidosł & 100,0 & $959,1 \quad(230,9)$ & 807,0 & 944,0 & 1093,8 & 100,0 & $982,9(235,1)$ & 826,0 & 968,0 & 1115,0 & 100,0 & $933,5 \quad(223,6)$ & 793,0 & 919,3 & 1071,0 \\
\hline TOTAL & 100,0 & $1460,7(312,7)$ & 1254,3 & 1436,8 & 1649,0 & 100,0 & $1500,0 \quad(322,6)$ & 1293,0 & 1477,5 & 1693,0 & 100,0 & $1418,6 \quad(296,1)$ & 1218,0 & 1398,0 & 1604,5 \\
\hline
\end{tabular}

*\%: Población consumidora: porcentaje de la población que ha comido alguna cantidad (ingesta mayor que cero) del alimento correspondiente. **g; cc. g: gramos (sólidos), cc: centímetros cúbicos (líquidos). † Líquidos: leche y bebidas comerciales procesadas de elaboración industrial (no incluye el agua de bebida); $\ddagger$ Sólidos: todos, excepto leche y bebidas comerciales procesadas de elaboración industrial.

ENICM 2001/2002: Encuesta de Nutrición Infantil de la Comunidad de Madrid 2001/2002. Instituto de Salud Pública, Consejería de Sanidad y Consumo, 2007.

Rev Esp Salud Pública 2007, Vol. 81, N. ${ }^{\circ} 5$ 
Tabla 2

Ingesta de energía y nutrientes en la población de 5-12 años de la Comunidad de Madrid. Total y por sexo. ENICM 2001/2002

\begin{tabular}{|c|c|c|c|c|c|c|c|c|c|c|c|c|}
\hline \multirow{4}{*}{ Energía/Nutriente } & \multicolumn{4}{|c|}{ Total $(n=1852)$} & \multicolumn{4}{|c|}{ Niños (n=958) } & \multicolumn{4}{|c|}{ Niñas $(n=894)$} \\
\hline & \multicolumn{4}{|c|}{ Ingesta (persona/día) } & \multicolumn{4}{|c|}{ Ingesta (persona/día) } & \multicolumn{4}{|c|}{ Ingesta (persona/día) } \\
\hline & \multirow{2}{*}{ Media (DE) } & \multicolumn{3}{|c|}{ Percentil } & \multirow{2}{*}{ Media (DE) } & \multicolumn{3}{|c|}{ Percentil } & \multirow{2}{*}{ Media (DE) } & \multicolumn{3}{|c|}{ Percentil } \\
\hline & & 25 & 50 & 75 & & 25 & 50 & 75 & & 25 & 50 & 75 \\
\hline Energía total (kcal) & $1905,9 \quad(377,5)$ & 1649,2 & 1887,4 & 2129,9 & $\begin{array}{ll}1980,9 & (388,7) \\
\end{array}$ & 1708,5 & 1961,6 & 2212,1 & \begin{tabular}{ll|}
1825,6 & $(347,9)$ \\
\end{tabular} & 1591,5 & 1814,5 & 2042,4 \\
\hline Hidratos de carbono $(\mathrm{g})$ & $222,0 \quad(51,8)$ & 186,7 & 219,1 & 252,1 & $232,4 \quad(53,9)$ & 197,0 & 228,0 & 263,8 & $210,9 \quad(46,9)$ & 179,5 & 209,4 & 239,8 \\
\hline Proteínas (g) & $82,3 \quad(18,1)$ & 69,8 & 81,0 & 93,9 & $85,2 \quad(18,4)$ & 72,4 & 84,2 & 96,8 & $79,2 \quad(17,2)$ & 67,3 & 78,1 & 90,5 \\
\hline Lípidos totales $(\mathrm{g})$ & $82,7 \quad(19,9)$ & 69,1 & 81,3 & 94,5 & $85,4 \quad(20,5)$ & 72,0 & 84,0 & 97,4 & $79,8 \quad(18,9)$ & 67,2 & 78,5 & 91,3 \\
\hline Ácidos grasos saturados (g) & 28,4 & 22,4 & 27,7 & 33,8 & $(9,1)$ & 23,1 & 28,8 & 35,2 & $(8,1)$ & 21,7 & 26,8 & 32,2 \\
\hline Ácidos grasos monoinsaturados (g) & 35,4 & 29,9 & 35,0 & \begin{tabular}{l|l}
40,2 \\
\end{tabular} & $(8,7)$ & 30,4 & 35,9 & 41,4 & $(7,9)$ & 29,1 & 34,0 & 39,0 \\
\hline Ácidos grasos poliinsaturados (g) & 10,5 & 7,6 & 10,0 & 12,7 & $(3,8)$ & 8,0 & 10,4 & 13,1 & $(3,9)$ & 7,3 & 9,3 & 12,2 \\
\hline Colesterol total (mg) & \begin{tabular}{|ll}
363,8 & $(149,6)$ \\
\end{tabular} & 252,1 & 350,8 & 448,6 & $380,4 \quad(154,5)$ & 265,9 & 367,9 & 473,3 & $346,0 \quad(142,2)$ & 242,5 & 333,2 & 426,6 \\
\hline Fibra (g) & 13,6 & 9,8 & 13,1 & 16,6 & $(5,4)$ & 10,3 & 13,4 & 16,8 & $(5,1)$ & 9,4 & 12,7 & 16,1 \\
\hline Calcio (mg) & $938,4 \quad(272,3)$ & 757,8 & 921,6 & 1094,7 & $960,8 \quad(276,4)$ & 773,6 & 942,7 & 1123,6 & $914,4 \quad(265,9)$ & 729,0 & 898,3 & 1071,5 \\
\hline Hierro (mg) & 10,9 & 8,6 & 10,5 & 12,5 & $(3,4)$ & 9,0 & 10,8 & 12,9 & $(3,1)$ & 8,3 & 10,0 & 12,1 \\
\hline Iodo $(\mu \mathrm{g})$ & $357,4 \quad(154,8)$ & 246,1 & 343,0 & 447,8 & $364,9 \quad(164,1)$ & 246,7 & 352,6 & 459,9 & $349,3 \quad(143,7)$ & 244,9 & 332,0 & 434,4 \\
\hline Magnesio (mg) & $235,6 \quad(53,7)$ & 200,6 & 232,4 & 267,8 & $243,1 \quad(56,3)$ & 206,2 & 239,3 & 275,8 & $227,4 \quad(49,5)$ & 193,0 & 224,5 & 258,1 \\
\hline Zinc (mg) & $(2,3)$ & 6,7 & 8,0 & 9,7 & $(2,4)$ & 7,0 & 8,3 & 9,9 & $(2,2)$ & 6,4 & 7,7 & 9,2 \\
\hline Sodio (mg) & $1639,8 \quad(584,0)$ & 1234,6 & 1556,1 & 1938,2 & $1720,3 \quad(598,1)$ & 1308,4 & 1638,6 & 2027,7 & $1553,5 \quad(556,2)$ & 1158,2 & 1481,0 & 1829,9 \\
\hline Potasio (mg) & $2961,5 \quad(729,7)$ & 2460,2 & 2915,9 & 3406,7 & $3042,1 \quad(754,6)$ & 2508,9 & 3014,9 & 3496,4 & $2875,1 \quad(692,0)$ & 2398,6 & 2852,2 & 3307,7 \\
\hline Tiamina (mg) & $(0,4)$ & 0,9 & 1,1 & 1,4 & $(0,4)$ & 0,9 & 1,1 & 1,4 & $(0,3)$ & 0,9 & 1,1 & 1,3 \\
\hline Riboflavina (mg) & $(0,5)$ & 1,5 & 1,7 & 2,1 & $(0,5)$ & 1,5 & 1,8 & 2,1 & $(0,5)$ & 1,4 & 1,7 & 2,0 \\
\hline Niacina (mg EN) & 29,1 & 23,5 & 28,4 & 33,9 & $(8,1)$ & 24,2 & 29,3 & 35,1 & $(7,4)$ & 22,8 & 27,1 & 32,6 \\
\hline Vitamina $B_{6}(\mathrm{mg})$ & $(0,5)$ & 1,1 & 1,3 & 1,7 & $(0,5)$ & 1,1 & 1,4 & 1,7 & $(0,5)$ & 1,1 & 1,3 & 1,6 \\
\hline Ácido fólico $(\mu \mathrm{g})$ & $158,0 \quad(62,7)$ & 114,8 & 149,4 & 191,7 & $160,2 \quad(65,6)$ & 115,8 & 150,5 & 194,0 & \begin{tabular}{ll|}
$155,6 \quad(59,4)$ \\
\end{tabular} & 113,5 & 148,3 & 189,0 \\
\hline Vitamina $\mathrm{B}_{12}(\mu \mathrm{g})$ & $4,5 \quad(3,7)$ & 3,0 & 4,0 & 5,2 & $4,6 \quad(3,8)$ & 3,1 & 4,1 & 5,3 & $(3,5)$ & 2,8 & 3,7 & 5,0 \\
\hline Vitamina C (mg) & $114,2 \quad(58,9)$ & 70,7 & 105,6 & 150,4 & $112,6 \quad(59,4)$ & 68,5 & 104,3 & 150,1 & $116,0 \quad(58,4)$ & 74,2 & 108,4 & 150,8 \\
\hline Vitamina A ( $\mu$ g ER) & $841,3 \quad(802,8)$ & 441,7 & 654,1 & \begin{tabular}{l|l}
985,3 \\
\end{tabular} & $886,5 \quad(865,1)$ & 454,0 & 673,2 & 1012,0 & $792,8 \quad(727,6)$ & 430,3 & 629,7 & 945,8 \\
\hline Retinol $(\mu \mathrm{g})$ & $430,2 \quad(717,9)$ & 165,6 & 255,7 & 382,4 & $472,5 \quad(790,1)$ & 174,9 & 269,3 & 408,6 & $384,8 \quad(628,8)$ & 160,0 & 246,4 & 346,2 \\
\hline Carotenos $(\mu \mathrm{g})$ & $2280,3(2036,3)$ & 917,5 & 1789,3 & 2999,6 & $2287,7(2012,0)$ & 942,9 & 1784,1 & 3091,9 & $2272,3(2063,1)$ & 893,8 & \begin{tabular}{|l|}
1790,9 \\
\end{tabular} & 2908,4 \\
\hline Vitamina D $(\mu \mathrm{g})$ & $(2,7)$ & 0,7 & 1,4 & 2,7 & $(2,7)$ & 0,7 & 1,4 & 2,7 & $(2,7)$ & 0,7 & 1,3 & 2,6 \\
\hline Vitamina E (mg $\alpha-t)$ & $(2,9)$ & 3,1 & \begin{tabular}{l|l}
4,6 \\
\end{tabular} & 7,1 & $(2,9)$ & 3,2 & 4,8 & 7,3 & $(2,9)$ & \begin{tabular}{l|l}
2,9 \\
\end{tabular} & \begin{tabular}{l|l}
4,4 & \\
\end{tabular} & 6,8 \\
\hline
\end{tabular}

DE: Desviación estándar; kcal: kilocalorías; g: gramos; mg: miligramos; $\mu$ g: microgramos; EN: equivalentes de niacina; ER: equivalentes de retinol. $\alpha$-t: -tocoferol. La vitamina E incluye sólo $\alpha$-tocoferol.

ENICM 2001/2002: Encuesta de Nutrición Infantil de la Comunidad de Madrid 2001/2002. Instituto de Salud Pública. Consejería de Sanidad, 2007.

menor porcentaje de la población (tabla 1). Del grupo de lácteos, del que prácticamente todos los niños/as $(99,8 \%)$ tomaban alguna cantidad, consumían de media 508,2 g/persona/día (unas 2 raciones/persona/día), la mayor parte leche, en concreto entera (270,9 cc/persona/día de media), seguida de yogur, otros derivados y postres lácteos, y queso (tabla 1). La ingesta media de verduras y hortalizas era de 88,9 g/persona/día (lo que equivale a una media ración/persona/día de ensalada variada o verdura cocida) y la de tubérculos 73,3 g/persona/día (una media ración de estos alimentos), casi exclusivamente patata (73,2 g/persona/día). Más del
$50 \%$ de la muestra tenía una ingesta media inferior a estas cantidades (tabla 1: P50 de verduras y tubérculos, respectivamente), el $7,5 \%$ (7,3\% de los niños y 7,7\% de las niñas) no habían comido nada de verduras ninguno de los dos días incluidos en la encuesta (tabla 1), el $96,2 \%$ ingería menos de $250 \mathrm{~g} /$ día y el 98,1\% menos de 300 g/día (tabla 3). La ingesta media de fruta fresca fue de 193,1 g/persona/día (lo que equivale a una pieza grande, por ejemplo manzana grande, o dos medianas, por ejemplo mandarina). Más del $50 \%$ estaba por debajo de esa cantidad (tabla 1: P50), el 7,9\% de los varones y el 5,7\% de las niñas no habían comido nada de fruta 
Tabla 3

Características de la dieta de la población de 5-12 años de la Comunidad de Madrid y objetivos nutricionales recomendados*, ${ }^{* *},{ }^{+}$. ENICM 2001/2002

\begin{tabular}{|c|c|c|c|c|}
\hline Nutriente/Alimento & Total & Niños & Niñas & Objetivos nutricionales $* * *,+$ \\
\hline Hidratos de carbono (\% energía) $\%$ & 43,6 & 43,9 & 43,3 & $>50^{*}$ \\
\hline Proteínas $(\%$ energía $) \div$ & 17,4 & 17,3 & 17,5 & $10-13^{*}$ \\
\hline Lípidos totales (\% energía) & 39,0 & 38,7 & 39,2 & $\leq 35^{*}$ \\
\hline Ácidos grasos saturados (\% energía $) \doteqdot$ & 13,3 & 13,3 & 13,3 & $\leq 10^{*}$ \\
\hline Ácidos grasos monoinsaturados (\% energía) & 16,8 & 16,6 & 17,0 & $20 *$ \\
\hline Ácidos grasos poliinsaturados (\% energía) & 5,0 & 4,9 & 5,0 & $5^{*}$ \\
\hline Razón ácidos grasos no saturados/saturados (media) & 1,7 & 1,7 & 1,7 & $\geq 2 *$ \\
\hline Fibra (g) (ingesta media/persona/día) & 13,6 & 14,0 & 13,1 & $>22 *$ \\
\hline Colesterol total (mg) (ingesta media/persona/día) & 363,8 & 380,4 & 346,0 & $<350^{*}$ \\
\hline $\begin{array}{l}\text { Densidad de colesterol (mg/1000 kcal) } \\
\text { (ingesta media/persona/día) }\end{array}$ & 191,1 & 192,5 & 189,5 & $<100^{*}$ \\
\hline $\begin{array}{l}\text { Verduras y hortalizas (\% de población) } \\
\text { Ingesta } \geq 250 \mathrm{~g} / \text { persona/día } \\
\text { Ingesta } \geq 300 \mathrm{~g} / \text { persona/día }\end{array}$ & $\begin{array}{l}3,8 \\
1,9\end{array}$ & $\begin{array}{l}3,9 \\
1,7\end{array}$ & $\begin{array}{l}3,7 \\
2,1\end{array}$ & $\begin{array}{l}\geq 250^{*} \\
\geq 300^{* *}\end{array}$ \\
\hline $\begin{array}{l}\text { Frutas frescas (\% de población) } \\
\text { Ingesta } \geq 300 \mathrm{~g} / \text { persona/día } \\
\text { Ingesta } \geq 400 \mathrm{~g} / \text { persona/día }\end{array}$ & $\begin{array}{r}19,8 \\
7,0\end{array}$ & $\begin{array}{r}18,2 \\
6,5\end{array}$ & $\begin{array}{r}21,5 \\
7,6\end{array}$ & $\begin{array}{l}\geq 300^{*} \\
\geq 400^{* *}\end{array}$ \\
\hline $\begin{array}{l}\text { Frutas frescas, verduras y hortalizas (\% de población) } \\
\text { Ingesta } \geq 400 \mathrm{~g} / \text { persona/día } \\
\text { Ingesta } \geq 550 \mathrm{~g} / \text { persona/día } \\
\text { Ingesta } \geq 700 \mathrm{~g} / \text { persona/día }\end{array}$ & $\begin{array}{r}21,9 \\
7,4 \\
2,2\end{array}$ & $\begin{array}{r}20,5 \\
7,1 \\
2,3\end{array}$ & $\begin{array}{r}23,4 \\
7,7 \\
2,0\end{array}$ & $\begin{array}{l}\geq 400^{+} \\
\geq 550^{*} \\
\geq 700^{* *}\end{array}$ \\
\hline
\end{tabular}

*, ** Objetivos nutricionales intermedios $(*)$ y finales $(* *)$ recomendados para la población española por la Sociedad Española de Nutrición Comunitaria, $2001^{36}$. ${ }^{+}$Ingesta conjunta de frutas frescas, verduras y hortalizas recomendada por la Organización Mundial de la Salud ${ }^{37}$.

$\$ \%$ energía: porcentaje de la ingesta total diaria de energía que se obtiene, por término medio, de los distintos macronutrientes.

ENICM 2001/2002: Encuesta de Nutrición Infantil de la Comunidad de Madrid 2001/2002. Instituto de Salud Pública, Consejería de Sanidad, 2007.

fresca en todo el día en ninguna de las dos ocasiones encuestadas (tabla 1), el 80,2\% ingería menos de $300 \mathrm{~g} /$ día y el 93,0\% menos de $400 \mathrm{~g}$ /día (tabla 3). La ingesta media de frutas frescas, verduras y hortalizas conjuntamente fue de $282,0 \mathrm{~g} /$ persona/día. En el $78,1 \%$ de los sujetos era menor de $400 \mathrm{~g} / \mathrm{día}$, en el $92,6 \%$ menor de $550 \mathrm{~g} /$ día y menor de 700 g/día en el 97,8\% (tabla 3). Considerando que una ración de legumbres son unos 60-80 g y una de huevos unos 50-60 g, la ingesta media de estos alimentos (tabla 1) era compatible con una frecuencia de consumo en esta población de aproximadamente una ración de legumbres por semana y unas 3 raciones/semana de huevos. Casi todos los niños/as habían comido a lo largo del día alguna cantidad del grupo de las carnes, del que se registró una ingesta media de 104,9 $\mathrm{g} /$ persona/día (una ración/persona/día), siendo la carne más consumida la de pollo $(44,8$ g/día), seguida de la de vacuno (34,7 g/día) y en tercer lugar, cerdo (18,2 g/día). La ingesta media de pescado era mucho menor que la de la carne $(35,5 \mathrm{~g} /$ persona/día, sobre todo pescado blanco: $28,0 \mathrm{~g} /$ día), lo que suponía menos de la tercera parte de una ración/persona/día, compatible con una ingesta en esta población inferior a las dos raciones/semana. El 49,3\% no había comido pescado ninguno de los dos días a los que se refería la entrevista. De aceites y grasas añadidas se observó una ingesta media de 27,5 g/persona/día (unas 3 raciones/día). El aceite de oliva fue el más empleado (supuso el $84,7 \%$ del consumo de aceite en esta población y el 98,1\% de los niños/as consumía alguna cantidad), seguido del de girasol (14,9\% del consumo de aceite; el $44,4 \%$ de los niños consume algo).

El 81,0\% de la población comía a lo largo del día algún producto de repostería (galletas, bollos, pasteles) y más el 92,4\% alguna chuchería, chocolate $u$ otro dulce 
Ingesta media de energía y nutrientes expresada como porcentaje de las ingestas recomendadas (\% IR)* en la población de 5 a 12 años de la Comunidad de Madrid. Total y por sexo. ENICM 2001/2002

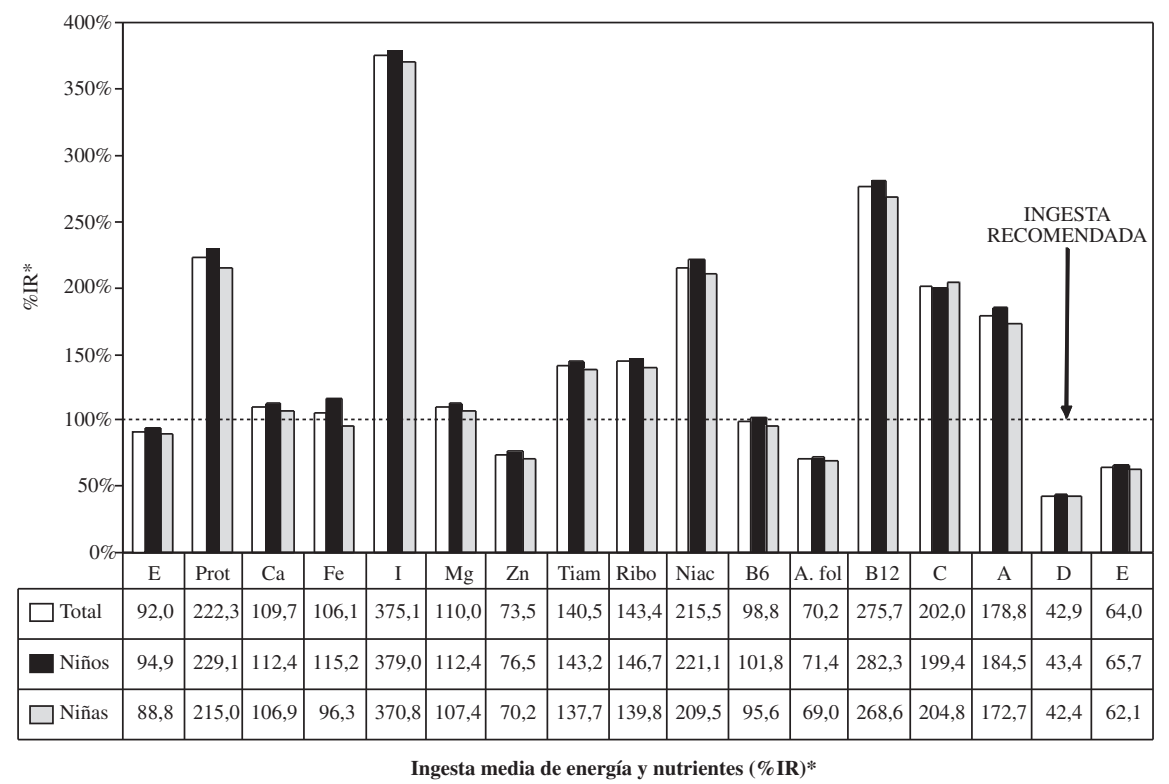

*IR: Ingestas recomendadas de energía y nutrientes para la población española (revisadas 2002) ${ }^{33}$.

E: energía; Prot: proteínas; Ca: calcio; Fe: hierro; I: Yodo; Mg: magnesio; Zn: zinc; Tiam: tiamina; Ribo: riboflavina; B6: vitamina B6; A. fol.: ácido fólico; B12: vitamina B12; C: vitamina C; A: vitamina A; D: vitamina D; E: vitamina E

ENICM 2001/2002: Encuesta de Nutrición Infantil de la Comunidad de Madrid 2001/2002. Instituto de Salud Pública, Consejería de Sanidad, 2007

(tabla 1). De aperitivos y chucherías saladas, alimentos precocinados o salsas se observó alguna ingesta en el $71,5 \%$ de los niños. Por último, el 64,2\% de la población estudiada tomaba a lo largo del día alguna cantidad de alguna bebida comercial procesada de elaboración industrial (el $28,5 \%$ sólo algo de zumo no natural procesado, el 19,4\% sólo refrescos y el 16,3\% ambas cosas), registrándose una ingesta media de 131,9 cc/persona/día (más de medio vaso).

\section{Ingesta de energía y nutrientes}

La ingesta media total diaria de energía resultante fue de $1.905,9 \mathrm{kcal} /$ persona/día (DE: 377,5 kcal/persona/día) (tabla 2), con la distribución de macronutrientes absoluta y relativa que se observa, respectivamente, en las tablas 2 y 3 . Por término medio el $43,6 \%$ de la energía diaria procedía de los hidratos de carbono, el $17,4 \%$ de las proteínas y un 39,0\% de los lípidos (13,3\% de ácidos grasos saturados, $16,8 \%$ de ácidos grasos monoinsaturados y $5,0 \%$ de poliinsaturados) (tabla 3). La ingesta y densidad/1000 kcal medias de colesterol estaba por encima de lo recomendado y la de fibra por debajo (tabla 3). En la figura 1 se presenta el porcentaje que representaban las ingestas medias de energía y nutrientes (tabla 2) de las ingestas recomendadas. La ingesta media de energía diaria fue un $92,0 \%$ de la ingesta diaria recomendada en esta población en España ${ }^{33}$, aunque en el $30,7 \%$ de la población estudiada $(36,0 \%$ de los varones y $24,9 \%$ de las niñas) fue superior a la recomendada para su grupo de 
edad y sexo. La de proteínas resultó ser más del doble de lo recomendado $(222,3 \%$ de la IR). Las ingestas medias de micronutrientes registradas se encontraban por encima de las recomendadas ${ }^{33}$, salvo para el zinc, ácido fólico y vitaminas D y E en ambos sexos, y hierro y vitamina $\mathrm{B}_{6}$ en las niñas (figura 1). El zinc es el mineral que presentaba la menor ingesta media diaria en comparación con las recomendaciones (73,5\% de la IR por término medio en el conjunto de la población) y entre las vitaminas destacaban la D, E y el ácido fólico, con una ingesta alimentaria media diaria que representaba el $42,9 \%, 64,0 \%$ y $70,2 \%$ respectivamente de las ingestas recomendadas (figura 1).

En general, los varones tienen ingestas absolutas de alimentos, energía y nutrientes mayores que la niñas, si bien, en términos relativos algunas diferencias disminuyen o desaparecen (tabla 3 y figura 1).

\section{DISCUSIÓN}

La ingesta media total diaria de alimentos en la población infantil de la Comunidad de Madrid es de 1.460,7 gramos/persona/día, que proporcionan de media 1.905,9 $\mathrm{kcal} /$ persona/día, con un $43,6 \%$ de hidratos de carbono, un $17,4 \%$ de proteínas, 39,0\% de lípidos (13,3\% grasas saturadas, $16,8 \%$ monoinsaturadas y $5,0 \%$ poliinsaturadas) y una ingesta media de colesterol y fibra de $363,8 \mathrm{mg}$ y $13,6 \mathrm{~g} /$ persona/día, respectivamente, lo que teniendo en cuenta los objetivos nutricionales para la población españo$\mathrm{la}^{36}$ representa un exceso de proteínas, grasas saturadas y colesterol, y un déficit de hidratos de carbono y fibra. El porcentaje de ácidos grasos poliinsaturados en la dieta está dentro de lo recomendado ${ }^{36}$ y el de monoinsaturados por debajo ${ }^{36}$, a costa del exceso observado en los saturados. Este desequilibrio en la distribución de las grasas en la dieta se refleja también en la razón de ácidos grasos no saturados/saturados de 1,7 , infe- rior al mínimo recomendado de $2^{36}$. Por otro lado, la ingesta de zinc, ácido fólico y vitaminas $\mathrm{D}$ y E en ambos sexos, y hierro y vitamina $\mathrm{B}_{6}$ en las niñas es también menor a la recomendada en esta población ${ }^{33}$.

Considerando las recomendaciones ${ }^{33}$, la ingesta media total diaria de energía $(92,0 \%$ de la IR) no resulta excesiva. La energía que un sujeto necesita diariamente para mantener un adecuado estado de salud depende de su gasto energético ${ }^{1 ; 33}$, determinado a su vez por (1) la actividad física desarrollada, (2) el efecto termogénico de los alimentos y (3) la energía necesaria para mantener el metabolismo basal, que es la fracción mayor de las necesidades energéticas e incluye los requerimientos para el mantenimiento de las funciones vitales y los requerimientos específicos para el adecuado desarrollo y crecimiento propios de cada fase o situación de la vida, aumentados por ejemplo en la edad infanto-juvenil, el embarazo y la lactancia. Los niveles recomendados para la población infantil en España $^{33}$ se han calculado asumiendo un nivel moderado de actividad física en esta población. Para una actividad física ligera, las necesidades energéticas han de reducirse un $10 \%$ y si la actividad desarrollada es intensa deben aumentarse un $20 \%{ }^{33}$. Por término medio, la actividad física que realiza la población infantil de la Comunidad de Madrid es reducida ${ }^{39}$. Esto podría explicar que la ingesta media de energía sea un $8 \%$ inferior al nivel medio recomendado, lo cual representaría, no una ingesta insuficiente sino una adaptación adecuada a un menor gasto energético. En cuanto a la posibilidad de que el recuerdo de 24 horas infraestime la ingesta real de energía, los estudios que lo han examinado no han obtenido resultados consistentes ${ }^{40-42}$. Al mismo tiempo el $30,7 \%$ de la población presenta una ingesta de energía superior al nivel recomendado para su grupo de edad y sexo, lo cual podría representar una ingesta excesiva, aunque para determinarlo es necesaria una evaluación individualizada más detalla- 
da en este subgrupo sobre los elementos que pueden modificar los requerimientos energéticos, como la actividad física. Esta evaluación sería recomendable ya que una ingesta excesiva mantenida a lo largo del tiempo junto al desarrollo de escasa actividad física es un factor de riesgo para el desarrollo de sobrepeso y obesidad ${ }^{1 ; 2}$.

En cuanto a los nutrientes la comparación de las ingestas dietéticas con los niveles recomendados es un indicador nutricional válido del riesgo de ingestas inadecuadas que puede existir en una población en un momento determinado ${ }^{34 ; 35}$, si bien hay que ser prudente en la interpretación de los resultados, pues aisladamente ni la comparación de la cantidad de los diferentes nutrientes que los sujetos obtienen a través de la ingesta alimentaria con las ingestas recomendadas ni ningún otro parámetro son suficientes por sí solos para diagnosticar inequívocamente la situación nutricional de un sujeto (es la valoración conjunta de parámetros dietéticos, antropométricos, bioquímicos y clínicos lo que permite juzgar el estado nutricional $)^{1 ; 25-27}$. Así, en el caso de los micronutrientes, cuando la ingesta media habitual de uno determinado en una población es igual o mayor a la ingesta recomendada, la probabilidad o riesgo de ingesta deficiente es muy bajo, mientras que cuanto menor es la ingesta media habitual en comparación con la recomendada mayor es el riesgo de que esta ingesta sea insuficiente ${ }^{34 ; 35}$. Por tanto, es deseable que los niveles nutricionales en la dieta se encuentren dentro de los niveles recomendados para que el riesgo sea el menor posible. En cuanto a la fibra, en España carecemos de una referencia sobre ingesta recomendada específicamente para la población infantil. Sin embargo, si examinamos los valores recomendados en países en los que sí existen, por ejemplo Estados Unidos $^{43}$, vemos que éstos (ingesta recomendada, concretamente, Adequate Intake, AI) son incluso mayores que los 22 g/día recomendados con carácter general en
España $^{36}$ : ingesta recomendada de fibra para niños y niñas de 4-8 años, 25 g/día ${ }^{43}$, ingesta recomendada para varones de 9-13 $a_{\tilde{n} o s}{ }^{43}, 31 \mathrm{~g} /$ día, e ingesta recomendada para niñas de 9-13 años, 26 g/día ${ }^{43}$, lo que supondría un déficit de fibra incluso mayor en la dieta de la población infantil de la Comunidad de Madrid.

La ingesta de energía y nutrientes observada en la población infantil de la Comunidad de Madrid es el resultado del tipo y cantidad de alimentos ingeridos. La principal dificultad para evaluar de forma exhaustiva la adecuación de la ingesta alimentaria es la inexistencia de referencias sobre las cantidades físicas a ingerir de los diferentes alimentos, estandarizadas, detalladas y específicas para la población infantil en España. No obstante, esto no impide realizar algunas consideraciones. Para algunos alimentos, como las frutas frescas, verduras y hortalizas, existen referencias precisas aceptadas internacionalmente sobre las cantidades mínimas a ingerir. De acuerdo con la evidencia científica actual, ninguna persona debería ingerir menos de 400 gramos de frutas frescas y verduras al día ${ }^{37}$. Otra presentación de esta recomendación es el conocido "5 al día"44, o la formulación del mensaje por la SENC: 3 ó más raciones de frutas al día y 2 ó más raciones de verduras y hortalizas al día ${ }^{36}$, que cuantitativamente traducen en los objetivos intermedios "al menos $300 \mathrm{~g}$ de frutas frescas y $250 \mathrm{~g}$ de verduras y hortalizas, al día"36 y en los objetivos finales "al menos $400 \mathrm{~g}$ de frutas frescas y $300 \mathrm{~g}$ verduras y hortalizas, al día"36. Por término medio, la ingesta conjunta de frutas, verduras y hortalizas en la población infantil de la Comunidad de Madrid es un 30\% inferior a los 400 gramos mínimos señalados, cantidad mínima que además no alcanza a ingerir el 78,1\% de la población. Además, en torno al 6-7\% de la población no había comido en todo el día nada de verduras, hortalizas o frutas frescas, lo que resulta elevado tratándose de alimentos básicos que se deben ingerir todos 
los días. La ingesta media de cereales, patatas, legumbres y pescados también está por debajo de las recomendaciones, que oscilan en las diferentes guías alimentarias ${ }^{45-48}$ entre las 4-6 raciones/día de cereales y patatas, 2-4 raciones/semana de legumbres y 34 raciones/semana de pescado. La ingesta de lácteos, huevos y grasas añadidas, a expensas fundamentalmente de los aceites, se encuentran dentro de los niveles recomendados, si bien, en el límite inferior en lo que se refiere a los lácteos. Por último, la ingesta de carnes y derivados cárnicos es superior a lo recomendado ${ }^{45-48}$.

En cuanto a los productos de repostería, dulces, chucherías saladas, alimentos precocinados y bebidas comerciales procesadas de elaboración industrial (productos de densidad nutricional o valor nutricional bajos y alto contenido en azúcares simples y/o grasas saturadas, colesterol, sodio $)^{49}$, es importante recordar que su presencia en las guías alimentarias (siempre bajo una indicación del tipo "consumo ocasional y moderado" o similar) y pirámides de alimentación (vértice) no debe interpretarse como la de los grupos alimentarios básicos, de densidad o valor nutricional altos (cereales y tubérculos; leche y derivados lácteos; verduras y hortalizas; frutas frescas; carnes, pescados, huevos y legumbres; grasas y aceites; y agua como bebida) $)^{27 ; 49}$. A diferencia de los grupos básicos, las indicaciones respecto a los productos de bajo valor nutricional no se refieren a cantidades o frecuencia con la que debemos ingerirlos para tener una dieta saludable, sino a límites en su consumo que se consideran compatibles con el mantenimiento del correcto equilibrio nutricional, por encima de los cuales aumenta el riesgo nutricional ${ }^{45-48}$. Es decir, al contrario que los grupos alimentarios básicos, la ausencia de estos productos en la dieta no generará ningún desequilibrio nutricional. En un contexto como el observado en la población infantil de la Comunidad de Madrid, en el que no se han alcanzado los niveles recomendados para algunos nutrientes esenciales (zinc, ácido fólico, hierro, vitaminas $\mathrm{D}, \mathrm{E} \mathrm{y} \mathrm{B}_{6}$, de escasa o nula presencia en los productos de bajo valor nutricional) al tiempo que se observan excesos para otros, como las grasas saturadas o el colesterol (presentes en estos productos en cantidades importantes) es cuestionable la presencia de productos no esenciales, de baja densidad nutricional. Las guías alimentarias más actualizadas ${ }^{45-48}$ señalan en sus recomendaciones clave que para obtener los niveles adecuados de todos los nutrientes esenciales manteniendo el balance energético se debe realizar una dieta variada a partir de alimentos de elevada densidad nutricional (grupos básicos), limitando la ingesta de grasas saturadas, grasas trans, colesterol, azúcares añadidos, sal y alcohol.

El escaso número de estudios de nutrición sobre población infantil en España realizados y/o publicados, pero sobre todo su diferente metodología (grupos de población considerados, marco muestral y tipo de muestreo, herramienta para recoger la información alimentaria, tablas de composición de alimentos empleadas, etc) dificulta la comparación de resultados ${ }^{50}$. En los últimos años los mayores estudios realizados sobre población infantil en España, que tienen o incluyen como objetivo principal la realización de una encuesta alimentaria y sobre los que existen datos publicados, son tres: el estudio CAENPE ${ }^{51}$, realizado en el periodo 1990-1992 sobre población escolar de 6 a 15 años de la Comunidad de Madrid, el Estudio Cuatro Provincias (4P) $)^{52-54}$, realizado en 1998-1999 sobre niños de 6-7 años de cuatro provincias españolas (Cádiz, Madrid, Orense y Murcia) y el estudio enKID $^{55 ; 56}$, realizado sobre una muestra de base poblacional de los residentes en España de 2 a 24 años (excepto Ceuta y Melilla). En comparación con estos estudios la ENICM registra una menor ingesta alimentaria total diaria. En los grupos básicos, destaca la menor ingesta en la ENICM de legumbres (11,2 g/persona/día, frente a los 
26,7, 19,6, 22,3 y 24,9 g/persona/día, en el CAENPE, 4P en la provincia de Madrid [4P-Madrid], enKID en el grupo de 6-9 años y enKID en el grupo de 10-13 años, respectivamente $)^{51 ; 53 ; 55}$, de cereales $(125,4$ g) en comparación con la observada en el CAENPE $(164,3 \mathrm{~g} / \text { persona/día })^{51}$ y el enKID (155,8 y 221,3 g/persona/día en los de 6-9 y 10-13 años, respectivamente) $)^{55}$, de frutas frescas $(193,1 \mathrm{~g})$ y pescados $(35,5 \mathrm{~g})$ respecto al CAENPE $(253,7$ y 77, 1 g/persona/día, respectivamente $)^{51}$ y el $4 \mathrm{P}-$ Madrid (342,3 y 45,6 g/persona/día, respectivamente $)^{53}$, y de verduras y hortalizas $(88,9 \mathrm{~g})$, muy por debajo de la registrada en el 4PMadrid (335,9 g/persona/día) ${ }^{53}$. Por el contrario la ingesta total del grupo de lácteos $(508,2 \mathrm{~g})$ es mayor en la población infantil de la Comunidad de Madrid que en el CAENPE $(410,4 \mathrm{~g} / \text { persona/día })^{51}$ y el enKID (473,4 y 423,6 g/persona/día los de 6-9 y 10-13 años, respectivamente) $)^{55}$, aunque no en comparación con el 4P-Madrid $(614,9 \mathrm{~g} / \mathrm{persona} / \mathrm{día})^{53}$. En cuanto a los productos no esenciales, también es en general menor la ingesta registrada en la ENICM en comparación con los otros estudios (productos de repostería: 87,6, 48,2 y 52,9 g/persona/día en el 4P-Madrid, enKID 6-9 y enKID 10-13 años, respectivamente; azúcares y dulces: 94,0, 27,9 y 30,1 g/persona/día en el CAENPE, enKID 6-9 y enKID 10-13 años, respectivamente; bebidas industriales: $242,9,435,5$ y $620,7 \mathrm{~g} / \mathrm{per}-$ sona/día en el 4P-Madrid, enKID 6-9 y 1013 años, respectivamente ${ }^{51,53,55}$. De forma consistente con el patrón alimentario, en la ENICM se registran en general ingestas medias absolutas de energía y nutrientes menores a las de los tres estudios indicados. Bastante menor a la registrada por el CAENPE (2604,0 kcal/persona/día) ${ }^{51}$, algo menor a la del 4P-Madrid (2077,7 kcal/persona/día) ${ }^{53}$ y más parecida a la registrada por el enKID para el grupo de 6 a 9 años $(1970,7 \mathrm{kcal} / \text { persona/día })^{56}$. Si bien, en términos relativos, los diferentes estudios coinciden en muchos de los aspectos negativos que se detectan en la dieta de la pobla- ción infantil, como el exceso de proteínas, grasas saturadas y colesterol, y el déficit alimentario de hidratos de carbono, fibra y vitamina $\mathrm{D}^{51,54,56}$. Y en el $4 \mathrm{P}$ también la ingesta insuficiente de vitamina $\mathrm{B}_{6}$ en ambos sexos ${ }^{54}$, así como en el enKID también el riesgo para la vitamina $\mathrm{E}$ en ambos sexos y el hierro en niñas ${ }^{56}$. No obstante, esto no puede interpretarse como una verdadera tendencia o evolución, ya que ninguno de estos estudios puede ser directamente comparado con la ENICM o entre ellos, debido a las diferencias en la metodología y en los grupos estudiados. De los tres estudios, el enKID ${ }^{55 ; 56}$ es el que presenta más similitudes metodológicas con la ENICM (por ejemplo, empleo del recordatorio de 24 horas), lo que es consistente con los resultados que se observan, los más parecidos a los de la ENICM. El 4P empleó para recoger la información alimentaria un cuestionario de frecuencia de consumo de alimentos ${ }^{52}$ que tiende a registrar ingestas mayores en comparación con el recuerdo de 24 horas $^{25-27}$ y el rango de edad considerado en el CAEN$\mathrm{PE}^{51}$ incluye niños hasta tres años mayores a los de la ENICM, lo que, al menos en parte, puede explicar que se registren en el CAENPE ingestas mayores a las de la ENICM.

La Encuesta de Nutrición Infantil de la Comunidad de Madrid 2001/2002 es el estudio poblacional de alimentación más amplio y actual realizado sobre una muestra representativa de la población infantil de una región que en el año 2002 incluía el $12,8 \%$ de la población infantil de 5 a 12 años de edad de España ${ }^{57}$, y más recientemente (2006) el 13,3\%57. Debido a las consecuencias negativas sobre la salud de una ingesta inadecuada habitual o mantenida es importante medir periódicamente la dieta de la población, siendo capaces de registrar la dieta actual y habitual y detectar los cambios y riesgos que eventualmente aparezcan (vigilancia), lo que requiere una herramienta fiable y la repetición de la medición con la misma metodología y con la frecuencia 
adecuada. Por sus propiedades ${ }^{25-27}$, el recuerdo de 24 horas es el método de encuesta alimentaria poblacional de elección en salud pública en numerosos organismos (National Health and Nutrition Examination Survey-NHANES del Departamento de Salud y Servicios Humanos en Estados Unidos, Canadian Community Health Survey-Nutrition en la administración pública de Canadá, National Children's Nutrition Survey en la de Nueva Zelanda o National Nutrition Survey en la australiana). En cuanto a la administración del recuerdo de 24 horas mediante entrevista telefónica numerosos estudios han confirmado que este método produce resultados comparables a otros métodos de encuesta basados en entrevistas "cara a cara" ${ }^{58-62}$. En nuestro ámbito geográfico también se han observado estimaciones similares ${ }^{63}$. Por último, aunque algunos estudios señalan que se puede obtener información fiable de niños de más de 7 años mediante la administración de recordatorios de 24 horas ${ }^{64 ; 65}$, otros autores consideran que antes de los 12 ó 13 años el niño todavía no es capaz de responder correctamente por sí solo un recordatorio de 24 horas, por desconocer los detalles de su alimentación o por ser incapaz de describirlos con la suficiente precisión ${ }^{66 ; 67}$, por lo que es necesario obtener la información de la persona al cuidado del niño y de su alimentación. En este sentido, los estudios que lo han examinado concluyen que la validez de la información referida por los padres muy elevada ${ }^{68}$, sobre todo en la medida en que esta información es proporcionada por el miembro de la familia que se encarga habitualmente de la alimentación del niño, y en nuestro estudio las entrevistas han sido completadas en más del $89 \%$ de esta manera.

En conclusión, los resultados presentados ofrecen una información muy relevante sobre la situación alimentaria y nutricional actual en la población infantil de 5 a 12 años de la Comunidad de Madrid. Se observan importantes desequilibrios en su dieta: ingesta inadecuada de grupos alimentarios básicos (notablemente baja en las frutas frescas, verduras y hortalizas), exceso de proteínas, grasas saturadas y colesterol y déficit de hidratos de carbono, fibra y algunos micronutrientes, desequilibrios que es necesario mejorar y cuyos determinantes es importante investigar.

\section{AGRADECIMIENTOS}

Agradecemos a Clotilde Vázquez y a Lydia Gorgojo el asesoramiento metodológico en el diseño de la encuesta de nutrición infantil.

\section{BIBLIOGRAFÍA}

1. Mann J, Truswell S. Essentials of Human Nutrition. Segunda ed. Gran Bretaña: Oxford University Press; 2004.

2. Shills ME, Shike M, Ross AC, Caballero B, Cousins RJ, Editores. Modern Nutrition in Health and Disease. Décima ed. Philadelphia: Lippincott Williams\&Wilkins; 2005.

3. Gonzalez CA, Navarro C, Martinez $\mathrm{C}$ et al. El Estudio Prospectivo Europeo Sobre Cancer y Nutricion (EPIC). Rev Esp Salud Publica. 2004;78(2):167-76.

4. Instituto de Salud Carlos III. Centro Nacional de Epidemiología. Área de análisis epidemiológico y situación de salud. Mortalidad y Encuesta de Morbilidad hospitalaria. España: Ministerio de Sanidad y Consumo [citado 6 de Marzo de 2007]. Disponible en: http://cne.isciii.es/htdocs/mortal/mortal2001/entradaweb.htm, 2007.

5. Instituto de Salud Pública. Informe del Estado de Salud de la Población de la Comunidad de Madrid, 2003. Madrid: Instituto de Salud Pública; 2003.

6. Miguel Benito A, Gandarillas A. Instituto de Salud Pública. Informe sobre la Mortalidad por enfermedades no transmisibles en la Comunidad de Madrid, 2000. Boletín Epidemiológico de la Comunidad de Madrid. Volumen 10, número 1. Madrid: Instituto de Salud Pública; 2004. 
7. Instituto de Salud Pública. Informe del Estado de Salud de la Población de la Comunidad de Madrid, 2004. Madrid: Instituto de Salud Pública; 2005.

8. Martín Vega A, Gandarillas Grande A, Zorrilla Torras B. Instituto de Salud Pública. Informe sobre la Mortalidad por enfermedades no transmisibles en la Comunidad de Madrid, año 2003. Boletín Epidemiológico de la Comunidad de Madrid. Volumen 12, número 4. Madrid: Instituto de Salud Pública; 2006.

9. Mokdad AH, Marks JS, Stroup DF, Gerberding JL. Actual causes of death in the United States, 2000. JAMA. 2004; 291 (10): 1238-45.

10. Banegas Banegas JR, Díez-Gañán L, RodriguezArtalejo F, Gonzalez Enriquez J, Graciani PerezRegadera A, Villar Alvarez F. Mortalidad atribuible al tabaquismo en España en 1998. Med Clin (Barc.). 2001; 117 (18): 692-94.

11. Banegas Banegas JR, Rodriguez-Artalejo F, Graciani A, Villar F, Herruzo R. Mortality attributable to cardiovascular risk factors in Spain. Eur J Clin Nutr. 2003; 57 (Suppl 1): S18-S21.

12. Banegas Banegas JR, Díez-Gañán L, Gonzalez Enriquez J, Villar Alvarez F, Rodriguez-Artalejo F. La mortalidad atribuible al tabaquismo comienza a descender en España. Med Clin (Barc). 2005; 124 (20):769-71.

13. Zorrilla-Torras B, Garcia-Marin N, Galan-Labaca I, Gandarillas-Grande A. Smoking attributable mortality in the community of Madrid: 19921998. Eur J Public Health. 2005; 15 (1): 43-50.

14. Puska P. Possibilities of a preventive approach to coronary heart disease starting in childhood. Acta Paediatr Scand Suppl. 1985; 318: 229-33.

15. Puska P. The North Karelia Project: from community intervention to national activity in lowering cholesterol levels and CHD risk. Eur Heart J Supplemments. 1999; 1(S): R1-R5.

16. Pietinen P, Lahti-Koski M, Vartiainen E, Puska P. Nutrition and cardiovascular disease in Finland since the early 1970s: a success story. J Nutr Health Aging. 2001; 5 (3): 150-154.

17. Puska P, Pietinen P, Uusitalo U. Part III. Can we turn back the clock or modify the adverse dynamics? Programme and policy issues. Influencing public nutrition for non-communicable disease prevention: from community intervention to national programme -experiences from Finland. Public Health Nutr. 2002; 5 (1A): 245-51.
18. Puska P. Nutrition and global prevention on noncommunicable diseases. Asia Pac J Clin Nutr. 2002; 11 (Suppl 9): S755-S758.

19. World Health Organization\&United Nations Children's Fund. A Healthy Start in life: Report on the Global Consultation on Child and Adolescent Health and Development. Ginebra: Organización Mundial de la Salud; 2002.

20. Rodriguez-Artalejo F, Banegas JR, Graciani A, Hernandez-Vecino R, del Rey-Calero J. Food supply versus household survey data: nutrient consumption trends for Spain, 1958-1988. Eur J Epidemiol. 1996; 12 (4): 367-71.

21. Rodriguez AF, Banegas JR, Graciani MA, Hernandez VR, Rey CJ. El consumo de alimentos y nutrientes en Espana en el periodo 1940-1988. Analisis de su consistencia con la dieta mediterranea. Med Clin (Barc). 1996; 106 (5): 161-68.

22. Aranceta J. Nutrición Comunitaria. Segunda ed. Barcelona: Masson; 2001.

23. Moreno LA, Sarria A, Popkin BM. The nutrition transition in Spain: a European Mediterranean country. Eur J Clin Nutr. 2002; 56 (10): 992-1003.

24. Nicholls II WL. Computer-assisted telephone interviewing: a general introduction. En: Groves RM, Biemer PP, Lyberg LE, Massey JT, Nicholls II WL, Waksberg J editors. Telephone survey methodology. Nueva York: John Wiley \& Sons Inc; 1988.

25. Margetts BM, Nelson M. Design concepts in nutritional epidemiology. Segunda Edición ed. New York: Oxford University Press; 1997.

26. Willet W. Nutritional Epidemiology. Segunda ed. Nueva York: Oxford University Press; 1998.

27. Serra Ll, Aranceta J, Mataix J. Nutrición en Salud Pública. Barcelona: Masson; 2006.

28. Beaton GH, Milner J, Corey P et al. Sources of variance in 24-hour dietary recall data: implications for nutrition study design and interpretation. Am J Clin Nutr. 1979; 32 (12): 2546-59.

29. Beaton GH, Milner J, McGuire V, Feather TE, Little JA. Source of variance in 24-hour dietary recall data: implications for nutrition study design and interpretation. Carbohydrate sources, vitamins, and minerals. Am J Clin Nutr. 1983; 37 (6): 98695.

30. Sempos CT, Johnson NE, Smith EL, Gilligan C. Effects of intraindividual and interindividual 
variation in repeated dietary records. Am J Epidemiol. 1985; 121 (1): 120-130.

31. Moreiras O, Carvajal A, Cabrera L, Cuadrado C. Tablas de composición de alimentos. Madrid: Ediciones Pirámide; 2001.

32. Sociedad Española de Nutrición Comunitaria. Pesos de raciones por grupos y medidas caseras. En: Sociedad Española de Nutrición Comunitaria y Sociedad Española de Medicina de Familia y Comunitaria. Consejos para una alimentación saludable. Madrid: SENC y semFYC; 2006.

33. Departamento de Nutrición. Universidad Complutense de Madrid. Ingestas recomendadas de energía y nutrientes para la población española (revisadas 2002). En: Moreiras O, Carvajal A, Cabrera L, Cuadrado C. Tablas de composición de alimentos. Novena edición ed. Madrid: Ediciones Pirámide; 2005.

34. Beaton GH. Uses and limits of the use of the Recommended Dietary Allowances for evaluating dietary intake data. Am J Clin Nutr. 1985; 41 (1): 155-64.

35. National Research Council. Recommended dietary allowances. Décima ed. Washington, DC: National Academy Press; 1989.

36. Sociedad Española de Nutrición Comunitaria. Objetivos nutricionales para la población española. En: Sociedad Española de Nutrición Comunitaria. Guías Alimentarias para la población española. Madrid: IM\&C Editores; 2001.

37. World Health Organization, Food and Agriculture Organization of the United Nations. Diet, Nutrition and the prevention of chronic diseases. Ginebra: World Health Organization; 2003.

38. SAS Institute Inc. The SAS System, Version 8.2, Cary, NC: SAS Institute Inc; 1999.

39. Instituto de Salud Pública. Consejería de Sanidad y Consumo. Comunidad de Madrid. Encuesta de Nutrición Infantil de la Comunidad de Madrid 2001/2002. Madrid: Instituto de Salud Pública; 2007 [datos no publicados].

40. Johnson RK, Driscoll P, Goran MI. Comparison of multiple-pass-24-hour recall estimates of energy intake with total energy expenditure determined by the doubly labeled water method in young children. J Am Diet Assoc. 1996; 96 (11): 1140-4.

41. Champagne CM, Baker NB, Delany JP, Harsha DW, Bray GA. Assessment of energy intake under reporting by doubly labeled water and observa- tions on reported nutrient intakes in children. J Am Diet Assoc. 1998; 98(4): 426-33.

42. Fisher JO, Johnson KJ, Lindquist C, Birch LL, Goran MI. Influence of body composition on the accuracy of reported energy intake in children. Obes Res. 2000; 8 (8): 597-603.

43. National Research Council. Dietary reference intakes for energy, carbohydrates, fiber, fat, fatty acids, cholesterol, proteins, and amino acids. Washington, DC: National Academy Press; 2002.

44. Centros para el Control y la Prevención de Enfermedades. 5 al día. Estados Unidos: 44.Departamento de Salud y Servicios Humanos [citado 14 de Marzo de 2007] Disponible en: http://www.cdc.gov/nccdphp/dnpa/5AlDia/inde x.htm, 2004.

45. Sociedad Española de Nutrición Comunitaria. Guías Alimentarias para la población española. Madrid: IM\&C Editores; 2001.

46. Health Canada. Canada's Food Guide. Otawa, Ontario, Canada: Health Canada; 2007.

47. U.S. Department of Health and Human Services, U.S. Department of Agriculture. Dietary Guidelines for Americans 2005. Sixth ed. Washington D.C.: Government Printing Office; 2005.

48. Nicklas T, Johnson R. Position of the American Dietetic Association: Dietary guidance for healthy children ages 2 to 11 years. J Am Diet Assoc. 2004; 104 (4): 660-677.

49. Drewnowski A. Concept of a nutritious food: toward a nutrient density score. Am J Clin Nutr. 2005; 82 (4): 721-32.

50. Gorgojo L, Guallar E, Martin-Moreno JM et al. Encuestas alimentarias en los niños españoles de edad escolar: analisis del periodo 1984-1994. Med Clin (Barc). 1999; 112 (10): 368-74.

51. Dirección General de Salud Pública del Ministerio de Sanidad y Consumo. Consumo de Alimentos y Estado Nutricional de la Población Escolar de la Comunidad Autónoma de Madrid (CAENPE). Madrid: Ministerio de Sanidad y Consumo; 1994.

52. Rodriguez AF, Garces C, Gil A et al. Estudio Cuatro Provincias: principales objetivos y diseño. Rev Esp Cardiol. 1999; 52 (5): 319-26.

53. Rodriguez-Artalejo F, Garces C, Gorgojo L et al. Dietary patterns among children aged 6-7 y in four Spanish cities with widely differing cardio- 
vascular mortality. Eur J Clin Nutr. 2002; 56 (2): 141-48.

54. Royo-Bordonada MA, Gorgojo L, Martin-Moreno JM et al. Spanish children's diet: compliance with nutrient and food intake guidelines. Eur J Clin Nutr. 2003; 57 (8): 930-939.

55. Serra Ll, Aranceta J. Alimentación infantil y juvenil. Estudio enKID. Vol. 3. Barcelona: Masson; 2002.

56. Serra L1, Aranceta J. Nutrición infantil y juvenil. Estudio enKID. Vol. 5. Barcelona: Masson; 2004.

57. Instituto Nacional de Estadística. Demografía y población.Cifras oficiales de población: Padrón Municipal.España: Instituto Nacional de Estadística; 2007 [citado 6 de Marzo de 2007]. Disponible en: http://www.ine.es/

58. Fox TA, Heimendinger J, Block G. Telephone surveys as a method for obtaining dietary information: a review. J Am Diet Assoc. 1992; 92 (6): 729-32.

59. Galasso R, Panico S, Celentano E, Del PM. Relative validity of multiple telephone versus face-toface 24-hour dietary recalls. Ann Epidemiol. 1994; 4 (4): 332-36.

60. Casey PH, Goolsby SL, Lensing SY, Perloff BP, Bogle ML. The use of telephone interview methodology to obtain 24-hour dietary recalls. J Am Diet Assoc. 1999; 99 (11): 1406-11.

61. Bogle M, Stuff J, Davis L et al. Validity of a telephone-administered 24-hour dietary recall in telephone and non-telephone households in the rural
Lower Mississippi Delta region. J Am Diet Assoc. 2001; 101 (2): 216-22.

62. Brustad M, Skeie G, Braaten T, Slimani N, Lund E. Comparison of telephone vs face-to-face interviews in the assessment of dietary intake by the $24 \mathrm{~h}$ recall EPIC SOFT program--the Norwegian calibration study. Eur J Clin Nutr. 2003; 57 (1): 107-13.

63. Galan I, Rodriguez-Artalejo F, Zorrilla B. Comparación entre encuestas telefónicas y encuestas «cara a cara» domiciliarias en la estimación de hábitos de salud y prácticas preventivas. Gac Sanit. 2004; 18 (6): 440-450.

64. Emmons L, Hayes M. Accuracy of 24-hr. recalls of young children. J Am Diet Assoc 1973; 62 (4): 409-15.

65. Samuelson G. An epidemiological study of child health and nutrition in a northern Swedish County. II. Methodological study of the recall technique. Nutr Metab 1970; 12 (6): 321-40.

66. van Horn LV, Stumbo P, Moag-Stahlberg A et al. The Dietary Intervention Study in Children (DISC): dietary assessment methods for 8- to 10-year-olds. J Am Diet Assoc. 1993; 93 (12): 1396-403.

67. Marr JW. Individual dietary surveys: purposes and methods. World Rev Nutr Diet. 1971; 13: 105-64.

68. Treiber FA, Leonard SB, Frank G et al. Dietary assessment instruments for preschool children: reliability of parental responses to the 24-hour recall and a food frequency questionnaire. J Am Diet Assoc. 1990; 90 (6): 814-20. 